\title{
EXTENSÃO UNIVERSITÁRIA, GÊNERO E ECONOMIA SOLIDÁRIA: INTERAÇÃO DE SABERES E CONSTRUÇÃO DA CIDADANIA
}

\author{
UNIVERSITY EXTENSION, GENDER AND SOLIDARY ECONOMY: \\ INTERACTION OF KNOWLEDGE AND CONSTRUCTION OF \\ CITIZENSHIP
}

\author{
Lindovon Dias Pessoa ${ }^{1}$ \\ Sharlene Dantas Moraes ${ }^{2}$ \\ Maria Josefa da Silva ${ }^{3}$ \\ Ligia Maria Alves Cavalcante ${ }^{4}$ \\ Joanacele G. R. Nobrega ${ }^{5}$ \\ Lindalva Alves Cruz
}

RESUMO: Este trabalho ressalta a experiência inovadora da extensão universitária no sertão da Paraíba, em especial, na Faculdade Santa Maria, PB. Nosso objetivo é apresentar, embora com resultados tímidos e parciais, o crescimento dos investimentos nas ações coletivas das mulheres e indicadores de empoderamento delas decorrente da interação dos saberes acadêmicos e populares. A construção envolve os estudantes, os professores, os colaboradores e os parceiros do projeto com as gestoras de economia solidária no campo e na periferia urbana. A metodologia a que recorremos foi a qualitativa, no sentido de apreender os resultados da observação participante, os depoimentos das destinatárias do projeto, dentre outros. Usamos como referencial teórico o entendimento de Paulo Freire sobre extensão universitária; de Paul Singer sobre economia solidária, além do

\footnotetext{
${ }^{1}$ Estudante de direito na FAFIC; estudante de especialização em docência do ensino superior na FSM e pesquisador do GEPEGESC. E-mail para contato: lindovon@hotmail.com.

2 Graduada em serviço social pela Faculdade Santa Maria. E-mail para contato: sharlene.oeste1000@hotmail.com.

${ }^{3}$ Bacharel em serviço social pela Faculdade Santa Maria; Especialista em atendimento educacional especializado-AEE, pela UNICOOP.

${ }^{4}$ Pós-graduada em gestão estratégica de pessoa pela FSM; pesquisadora do GEPEGESC; estudante de especialização em docência do ensino superior na FSM. E-mail para contato: ligiacavalcantecz@hotmail.com.

${ }^{5}$ Mestranda pela UNIGRENDAL; assistente social e coordenadora do IMJOB. E-mail para contato: joanacelegorgonho@hotmail.com.

${ }^{6}$ Professora e doutora em sociologia pela UFPE; professora dos cursos de serviço social e medicina da FSM; líder institucional do grupo de pesquisa em gênero e economia solidária e cidadania (GEPEGESC) da FSM; pesquisadora responsável pela linha "gênero, economia solidária e cidadania". E-mail para contato: lindasorella@hotmail.com.
} 
entendimento da igualdade de gênero, para jogar luzes sobre as ações direcionadas a estimular empreendimentos de economia solidária autogestados, principalmente, por mulheres no município de Cajazeiras (PB). A proposta, em andamento, consiste de um projeto de extensão intitulado Produção e comercialização nos empreendimentos de economia solidária, o qual faz abordagem de gênero, agroecológica e técnico-operativa e é desenvolvido pelo grupo de estudo, pesquisa e extensão em gênero e economia solidária e cidadania (GEPEGESC) em parceria com o Instituto Maria José Batista Lacerda (IMJOB). O referido projeto apoia as mulheres nos processos de produção e comercialização. Para tanto, entre outras atividades, desenvolve cursos de formação nas áreas de gênero e economia solidária, gestão de pequenos negócios e empreendedorismo; auxilia no esforço por fomento para o crescimento da produção; viabiliza a integração dos saberes entre academia e comunidade. O propósito é qualificá-las no combate à pobreza e à desigualdade de gênero. As partes envolvidas com as atividades de extensão constroem a prática de cunho político-pedagógico e estão imbuídas do objetivo da autogestão.

PALAVRAS CHAVE: extensão universitária; economia solidária; gênero e cidadania.

ABSTRACT: This work highlights the innovative experience of university extension in the backlands of Paraiba, in particular, at Santa Maria College, PB. Our 100ommun to 100ommunit, although with timid and partial results, the growth of investments in the collective actions of women and indicators of empowerment resulting from the interaction of academic and popular knowledge. Construction involves students, teachers, employees and the partners of the 100ommuni with the managers of solidarity economy in the field and in the urban periphery. The methodology we used was qualitative, in the sense of apprehending the results of the participant observation, the statements of the beneficiaries of the 100ommuni, among others. We use as theoretical reference Paulo Freire's understanding of university extension; of Paul Singer on solidarity economy, as well as the understanding of gender equality, to throw light on actions aimed at stimulating solidarity-based self-directed ventures, mainly by women in the municipality of Cajazeiras (PB). The proposal, in progress, consists of na extension 100ommuni entitled Production and commercialization in enterprises of solidarity economy, which takes a gender, agroecological and technical-operative approach and is developed by the group of study, research and extension in gender and solidarity economy and citizenship (GEPEGESC) in partnership with the Maria José Batista Lacerda Institute (IMJOB). This 100ommuni supports women in the production and marketing processes. For this, among other activities, it develops training courses in the 100ommu of gender and solidarity economy, small business management and entrepreneurship; assists in the effort to foster production growth; enables the integration of knowledge between academy and 100ommunity. The purpose is to qualify them in the fight against poverty and gender inequality. The portions involved in outreach activities build the political-pedagogical practice and are imbued with the goal of selfmanagement. 
KEY WORDS: university extension; solidarity economy; gender and citizenship. 


\section{INTRODUÇÃO}

O Brasil está mergulhado em uma crise de dimensão desproporcional cujas consequências vêm aumentando a vulnerabilidade social perceptível nos diferentes estados e municípios. As causas são as mesmas: a concentração de renda por um grupo minoritário no país, a corrupção e a desigualdade de condições de acesso aos bens e serviços.

A Faculdade Santa Maria, embora instituição de educação privada, preocupase com o desenvolvimento da região. Ela tem como missão formar cidadãos que respondam às demandas da sociedade. Dessa perspectiva, busca contribuir com o fortalecimento das iniciativas que apontem para resolução dos problemas sociais das comunidades, por exemplo, geração de emprego e renda para as pessoas em situação de exclusão social - realidade desafiadora para as mulheres do meio popular no sertão paraibano.

O projeto de extensão intitulado Produção e comercialização nos empreendimentos de economia solidária: uma abordagem agroecológica e técnico-operativa colabora com a construção de saídas para as mulheres autogestoras de economia solidária, desenvolvendo um plano de formação proposto pelos próprios empreendimentos. No processo, consideram-se as habilidades das mulheres e homens de cada negócio, de modo que, ao final, seja possível alavancar a produção e o comércio dos produtos conforme os princípios da economia solidária.

Tais iniciativas, além de proporcionar a troca de saberes entre acadêmicos e comunitários, se destinam não só a contemplar um viés econômico, mas também a vislumbrar a inclusão social, o fortalecimento da organização grupal, da autogestão, de autonomia nas decisões, enfim, o empoderamento das mulheres como sujeitos e protagonistas de suas histórias para a vivência da cidadania. 


\section{FUNDAMENTOS QUE EMBASAM A EXPERIÊNCIA EXTENSÃO}

A extensão universitária não é prática recente, mas, no último século, ganhou mais espaço nas universidades e demais instituições de ensino superior, a fim de se equilibrar o tripé pesquisa, ensino e extensão como prática indissociável na construção do conhecimento. Contudo, o entendimento que considera a extensão universitária como processo educativo, de inclusão cultural, que possibilita a relação de crescimento simultâneo entre a universidade e comunidade, é mais recente.

No Brasil, por exemplo, só após a promulgação da Lei de Diretrizes e Bases da Educação (LDB) de 1996 (BRASIL, 1996), a indissociabilidade entre os três campos de construção do conhecimento passou a ser o pilar da educação. O teórico de influência nesse entendimento e, indispensável neste debate, é Paulo Freire, que revolucionou a educação com seu método, no século passado. Na sua concepção, a construção do conhecimento não é mera transmissão de conteúdos de forma verticalizada, na qual o transmissor emite para o receptor o que este não sabe; para Freire o conhecimento é um processo que se dá simultaneamente.

[...]educar e educar-se, na prática da liberdade, é tarefa daqueles que sabem que pouco sabem - por isto sabem que sabem algo e podem assim chegar a saber mais - em diálogo com aquêles que, quase sempre, pensam que nada sabem, para que êstes, transformando seu pensar que nada sabem em saber que pouco sabem, possam Igualmente saber mais[...]. (Freire, 2006, p. 25).

Freire (2006), ao se referir ao conhecimento, diz que esse não seria conhecimento se entendido como vindo daquele que se julga sabedor até aqueles que se julgam não sabedores. Na verdade, ele se "constitui nas relações homemmundo, relações de transformação, e se aperfeiçoa na problematização crítica destas relações" (Freire, 2006, p. 36).

Diante do exposto, podemos inferir, há nesse processo uma práxis, pois interagir, conhecer a pessoa humana em suas relações culturais em qualquer 
circunstância possibilita a apreensão dela como sujeito (e não, coisa), pois conhecimento é um ato humano. À medida que há humanização, segundo alguns autores, a visão científica pode mover-se na busca pela inquietação do sujeito, para que este, com base na sua curiosidade, estabeleça metodologias para mudança da realidade. (Carvalho, Albuquerque e Gondim, 2011).

Corroborando o pensamento de Freire, o Fórum Nacional de Pró-Reitores de 1987 inovou a prática universitária ao fortalecer o conceito de extensão:

\begin{abstract}
A Extensão é uma via de mão-dupla, com trânsito assegurado à comunidade acadêmica, que encontrará, na sociedade, a oportunidade de elaboração da práxis de um conhecimento acadêmico. No retorno à Universidade, docentes e discentes trarão um aprendizado que, submetido à reflexão teórica, será acrescido àquele conhecimento. Esse fluxo, que estabelece a troca de saberes sistematizado, acadêmico e popular, terá como consequências a produção do conhecimento resultante do confronto com a realidade brasileira e regional, a democratização do conhecimento acadêmico e a participação efetiva da comunidade na atuação da Universidade. (Fórum Nacional, 1987).
\end{abstract}

Assim, a extensão é o caminho para construção de novos conhecimentos produzidos no diálogo horizontal entre a instituição do ensino superior e a comunidade, de modo a criar condições para a emancipação dos grupos coletivos empenhados na construção da cidadania.

Nessa direção, convém refletir sobre economia solidária, que tem como principal protagonista as mulheres no campo e na cidade. Tanto da perspectiva teórica quanto da prática, tal economia é apresentada como modelo que estabelece o exercício de novas relações produtivas e de consumo estruturadas com base na organização da sociedade civil, no sentido de transformar as relações de produção e sociais. Ela está, portanto, na contramão do modelo vigente e hegemônico, o qual, segundo Polanyi (1944) citado por Boff (2014), tem proporcionado a competição mais agressiva de todos os tempos, sem qualquer sentido de partilha, de cooperação, de compaixão, de solidariedade. Para Boff (2014), nesse processo, 
tudo se tornou mercadoria, até a água, as sementes, os órgãos humanos, a amizade, o amor, a morte, dentre outros elementos e valores.

Quanto à conceituação ou definição de economia solidária, não há consenso. Contudo, para autores como Singer (2003), (2002), todas as iniciativas nesse sentido se concentram em torno da ideia de solidariedade em contraposição ao individualismo. Outro autor (Ortiz, 2001) defende que tal modelo recobre diferentes modos de organização nos quais os cidadãos se propõem criar as próprias formas de produzir, para ter acesso a bens e serviços de qualidade pelo mais baixo custo em dinâmica coletiva, solidária e de reciprocidade que articule os interesses individuais e grupais (tradução livre). Conforme o entendimento de Singer (2002), a economia solidária é

[...] modelo de produção, consumo e distribuição alternativa ao capitalismo, criado e recriado periodicamente pelos que se encontram marginalizados do mercado de trabalho [...], tais atividade casa o princípio da unidade entre posse e uso dos meios de produção e distribuição com o princípio da socialização destes meios (p. 12).

Do ponto de vista de gênero, no modelo e na lógica de produção capitalista, a presença das mulheres foi marcada pela divisão sexual do trabalho e pelas relações patriarcais. Prevalece, nas análises sobre suas ações, a percepção baseada nas relações familiares, principalmente, no papel de mães, esposas e donas de casa. Para Carrasco (1999), a economia capitalista faz um recorte de gênero, caracterizando as mulheres como dependentes do marido ou do pai, improdutivas e irracionais.

As relações de dominação proveniente do modelo patriarcal fizeram a família ser compreendida de forma homogênea: o homem, representante dos interesses do conjunto, detém o poder de decisão. Daí, organizou-se a hierarquia de gênero e geração, centrada no poder do macho sobre a fêmea. Essas relações patriarcais associadas à lógica capitalista entrelaçaram-se e caracterizaram uma visão da economia e do trabalho restrita ao âmbito de mercado. Reduzido ao econômico o que se realiza na chamada esfera produtiva, atribuir valor de troca e de mercantilização coube ao elemento masculino. Tal entendimento se sustenta no 
discurso ainda vigente de que as mulheres foram destinadas à esfera privada como parte do determinismo biológico vinculado à maternidade. Isso reforça o não reconhecimento da produção doméstica e do papel econômico do trabalho das mulheres na família (Nobre, 2002; Silva, 2009; Strassmann, 2002). Essa realidade, alimentada ideologicamente como fruto da natureza, na verdade, foi estruturada pela relação social específica entre homens e mulheres, baseada em uma forma de divisão do trabalho: a divisão sexual. Segundo Kergoat (1996), a referida divisão do trabalho se organizou com base em dois princípios: a separação de trabalho do homem e da mulher e a hierarquização do trabalho dos homens - esta atividade mais valorizada. Disso têm decorrido práticas sociais distintas que perpassam todos os segmentos sociais. Uma sociedade sexuada, estruturada transversalmente pelas relações de gênero, significa a "discriminação das mulheres pelo trabalho mais valorado dos homens" (Hirata \& Kergoat, 2003, p. 30).

A nossa prática de extensão fortalece a desconstrução das estruturas culturais de opressão das mulheres e, ao mesmo tempo, promove o empoderamento delas na construção de novas relações sociais de produção e de consumo, bem como estimula a construção de novos saberes.

\section{INSTITUIÇÕES DE APOIO À EXTENSÃO}

A Faculdade Santa Maria (FSM) está localizada na BR 230, km 504, município de Cajazeiras (PB). Foi concebida como proposta educacional em 13 de abril de 2000 e iniciou suas atividades acadêmicas em 20 de julho de 2002. O referido município, vale ressaltar, está localizado no polígono da seca, que castiga severamente seus habitantes. Entretanto, a adversidade natural não constitui a principal razão para os processos de exclusão social da grande maioria daquela população.

De acordo com o Regimento Interno da FSM (2002), faz parte do seu compromisso promover a educação integral do ser humano pelo cultivo do saber, sob diversas formas e modalidades, como exercício e busca permanente da 
verdade; ser uma instituição social e democrática, aberta a todas as correntes do pensamento, centro dos princípios da liberdade com responsabilidade, justiça e solidariedade humana; incentivar o trabalho de pesquisa e de investigação científica, visando ao desenvolvimento da ciência e da tecnologia e à criação e difusão da cultura; desenvolver o entendimento do homem, da mulher [grifo nosso] e do meio em que vivem; promover a extensão aberta à participação da população, visando à difusão das conquistas e dos benefícios resultantes da criação cultural e da pesquisa científica e tecnológica geradas na instituição, dentre outros.

Frente ao exposto, em 2012, com a nossa inserção na referida IES, isto é, da professora doutora Lindalva Alves Cruz e da professora doutora Pavlova Christinne C. Lima, ambas recém-chegadas da conclusão dos seus doutorados - aquela em sociologia pela Universidade Federal de Pernambuco; esta em administração de empresas pela Universidade de Salamanca (USAL-Espanha) -, foi criado o grupo de estudo, pesquisa e extensão em gênero e economia solidária e cidadania (GEPEGESC).

O GEPEGESC trabalha na perspectiva de gênero, economia solidária e cidadania. O seu reconhecimento pelo Conselho Nacional de Desenvolvimento Científico e Tecnológico (CNPQ), em 2016, possibilitou a inclusão de outras temáticas, como gestão de pequenas empresas e meio ambiente. As ações por ele desenvolvidas estão voltadas, de modo especial, para empreendimentos de economia solidária autogestados por mulheres, considerados como alternativa no enfrentamento do desemprego na região e como espaço de construção da cidadania das empreendedoras.

O projeto de extensão supracitado logo se constituiu em possibilidade de interação dos saberes entre as comunidades e a IES; contudo, não dispunha de recurso financeiro suficiente para viabilizar, com eficácia, a prática de extensão. Em outubro de 2013, foi fundado o Instituto Maria José Batista Lacerda (IMJOB), instituição não governamental, sem fins econômicos, criada para fortalecer a responsabilidade social da Faculdade Santa Maria e estabelecer relação de parceria com a pesquisa e a extensão.

O IMJOB tem como missão otimizar e viabilizar novas ideias, integrando pessoas, construindo dignidade para transformação social. Com esse intuito, em 
2014, implantaram-se diversos trabalhos sociais que resultariam em benefício às comunidades carentes no sertão da Paraíba, bem como apoiariam os projetos de extensão da FSM. O referido instituto, em 2015, em parceria com a Fundação Assistência Médica Internacional (AMI) de Portugal, conseguiu recursos para alavancar o projeto de extensão já mencionado, o qual começou a ser executado em 2016.

\section{EMPREENDIMENTOS COMTEMPLADOS PELO PROJETO DE EXTENSÃO}

O GEPEGESC, em parceria com o IMJOB, mantinha no momento estreita relação com 14 empreendimentos no município de Cajazeiras. Mas, para o mencionado projeto, foram selecionados apenas quatro - aqueles primeiros visitados em razão da proximidade com a FSM e da continuidade de um trabalho em andamento desde 2012.

O empreendimento Grupo de Mulheres Doce Vida, com sede na comunidade Cajazeiras Velha, zona rural, situada a $17 \mathrm{~km}$ da cidade de Cajazeiras, é formado por 31 famílias de pequenos proprietários de terra que desenvolvem atividades econômicas, como fruticultura irrigada, criação de galinhas, de bovinos e de suínos e plantam hortaliças. O grupo surgiu em 2008, com o objetivo de construir alternativas de emprego e renda. Desde então, as mulheres têm-se dedicado ao beneficiamento de frutas, à fabricação de doces, de bolos, de cocadas e geleias, além da produção de sequilhos, pamonhas, dentre outros. O grupo produz e comercializa coletivamente e de forma sustentável.

O outro empreendimento, As Louceiras, com sede no bairro São José, na cidade de Cajazeiras, fabrica louças em cerâmica e diferentes tipos de peças ornamentais. É formado por nove mulheres e quatro homens, quase todos com baixo índice de escolaridade, na faixa etária entre 30 e 50 anos. Eles trabalham há décadas nessa atividade artesanal, considerada a mais antiga do sertão paraibano.

O terceiro empreendimento, Grupo Arte Vida, tem sede na comunidade Caiçara II, a $21 \mathrm{~km}$ da cidade de Cajazeiras. Tal comunidade é um povoado formado 
por 35 famílias de pequenos produtores rurais - 50\% são proprietários de poucos hectares de terra; os demais trabalham em regime de meeiros (dividem o que produzem com os donos das terras), cultivando milho e feijão para consumo local, criando pequenos rebanhos de bovinos, de suínos e aves. Entretanto, as mulheres constituíram este grupo desde 2008, para produção de artesanato de diferentes modelos: crochê, pinturas, chapéus de palha, artesanato em papel, tapetes em cordão, bordados em ponto cruz, toalhas, dentre outros. A comercialização é realizada em feiras livres e ou por encomenda, em página na internet ou por telefone.

O quarto empreendimento, Grupo das Mulheres Produtoras de Hortaliças, com sede na comunidade Serra da Arara I, surgiu na comunidade rural de Serra da Arara II, em 2008, com o objetivo de unir as mulheres e homens em busca de alternativas de produção sustentável. Ali se fortaleceu a produção de hortaliças sem veneno para consumo das famílias e comercialização do excedente; cresceu também a criação de galinha-de-capoeira, muito procurada na região. A população residente nas duas comunidades é de 97 famílias, as quais sobrevivem da agricultura de serqueiro e da criação de animais, isto é, de bovinos, ovinos e aves. As famílias têm baixo índice de escolaridade e seu maior sofrimento é a falta de água potável.

\section{NARRAÇÃO SOBRE A EXTENSÃO}

O projeto Formação, produção e comercialização nos empreendimentos de economia solidária: uma abordagem agroecológica de gênero e técnico-operativa se constitui em um conjunto de atividades temporárias de caráter técnico, educativo e cultural, desenvolvido pelo GEPEGESC em parceria com o IMJOB. Tais ações se desenvolvem em três eixos: formação das empreendedoras; entrega de materiais e equipamentos para os empreendimentos; produção de um livro. Neste artigo, apresentamos os dois primeiros eixos. 
No mês de fevereiro de 2017, início da execução do projeto, foram entregues a cada empreendimento os equipamentos e os materiais de acordo com a necessidade das empreendedoras, mas destinados à melhoria da estrutura física, da qualidade dos produtos e ao desenvolvimento da produção.

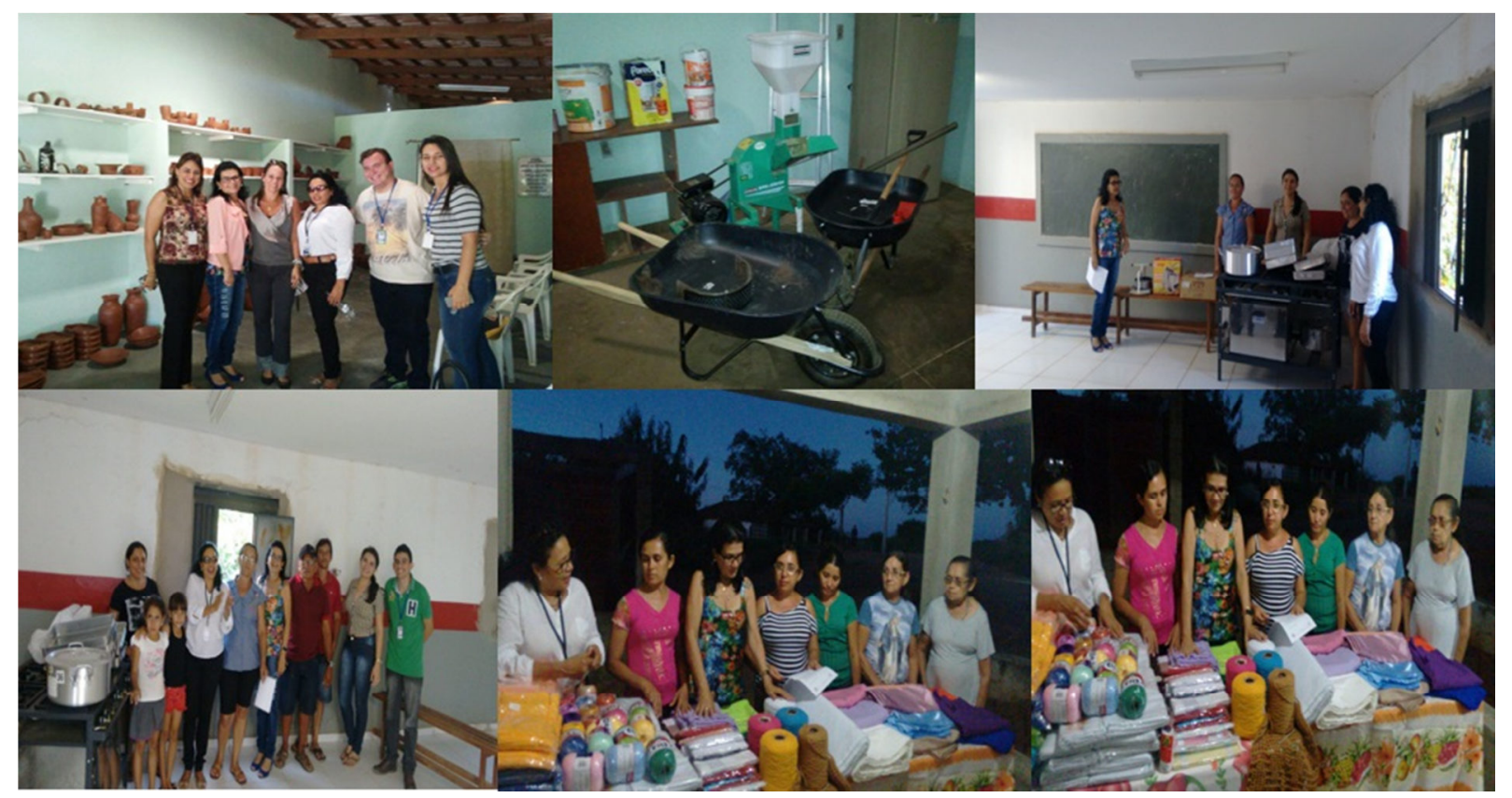

FONTE: Autores.

Ao mesmo tempo, iniciou-se a atividade de formação, que vem sendo desenvolvida em minicursos, workshop, oficinas e seminários, cada um com duração de oito horas. Os conteúdos contemplam as seguintes temáticas: agroecologia e desenvolvimento sustentável; gênero, economia solidária e cidadania; planejamento organizacional; formação de preço e venda; qualidade de vida; políticas públicas para mulheres; motivação; empreendedorismo; exposição e comercialização dos produtos em feiras e exposições. Tais conteúdos foram organizados em função da necessidade das empreendedoras, isto é, as mulheres escolheram as temáticas que auxiliariam seu negócio quanto à organização, à produção e à comercialização nos seus espaços de trabalhos e nas feiras.

Para as atividades específicas, como a produção de louças em cerâmicas, além da formação geral, programou-se um curso próprio para ceramistas no local onde se desenvolviam as atividades das louceiras. À medida que outros 
empreendimentos tomaram consciência dos benefícios trazidos pela formação, foram solicitando sua participação. A propósito, os cursos, pela sua relevância, poderiam perfeitamente ser estendidos aos demais gestores, desde que houvesse acomodação para todos, transporte e alimentação.

A solicitação para a abertura estreitou a parceria com o Programa de Ação Social e Políticas Públicas (PASPP), da diocese de Cajazeiras, e com a Central das Associações dos Assentamentos do Alto Sertão Paraibano (CAASP), dentre outros movimentos que, prontamente, assumiram parte das despesas relacionadas à acomodação dos participantes. Assim, mais de 60 pessoas provenientes dos empreendimentos de todo o sertão paraibano têm participado dos cursos de formação. Embora as mulheres predominem, estão presentes também os gestores de economia solidária - para os organizadores do projeto, dado muito positivo não previsto inicialmente, mas de grande repercussão. Tais encontros com número maior de participantes ampliaram a possibilidade de troca de experiência e conhecimento, sobretudo, em relação às dificuldades enfrentadas pelos gestores, cada um em seu ambiente e em seu processo de produção e comercialização, o que fortaleceu a busca de saídas coletivas.

As ações de formação foram realizadas por professores, técnicos e especialistas, os quais recebiam o apoio dos extensionistas e estagiários do IMJOB. Assim, de um lado, o projeto tem capacitado e instrumentalizado as mulheres autogestoras em economia solidária para produção e comercialização dos seus produtos; do outro, tem proporcionado aos extensionistas e estagiários, que são de diferentes cursos, enriquecimento no seu processo formativo, por consequência estarão mais aptos a responder às demandas sociais.

Os minicursos acontecem em lugares diferentes: às vezes, na faculdade; outras, em centros comunitários e até nas instalações dos próprios empreendimentos. Até o último mês de junho, conseguimos realizar cinco encontros; em alguns foram expostos os produtos (artesanato, alimentação e cerâmica) para a apreciação de promotores de eventos. 


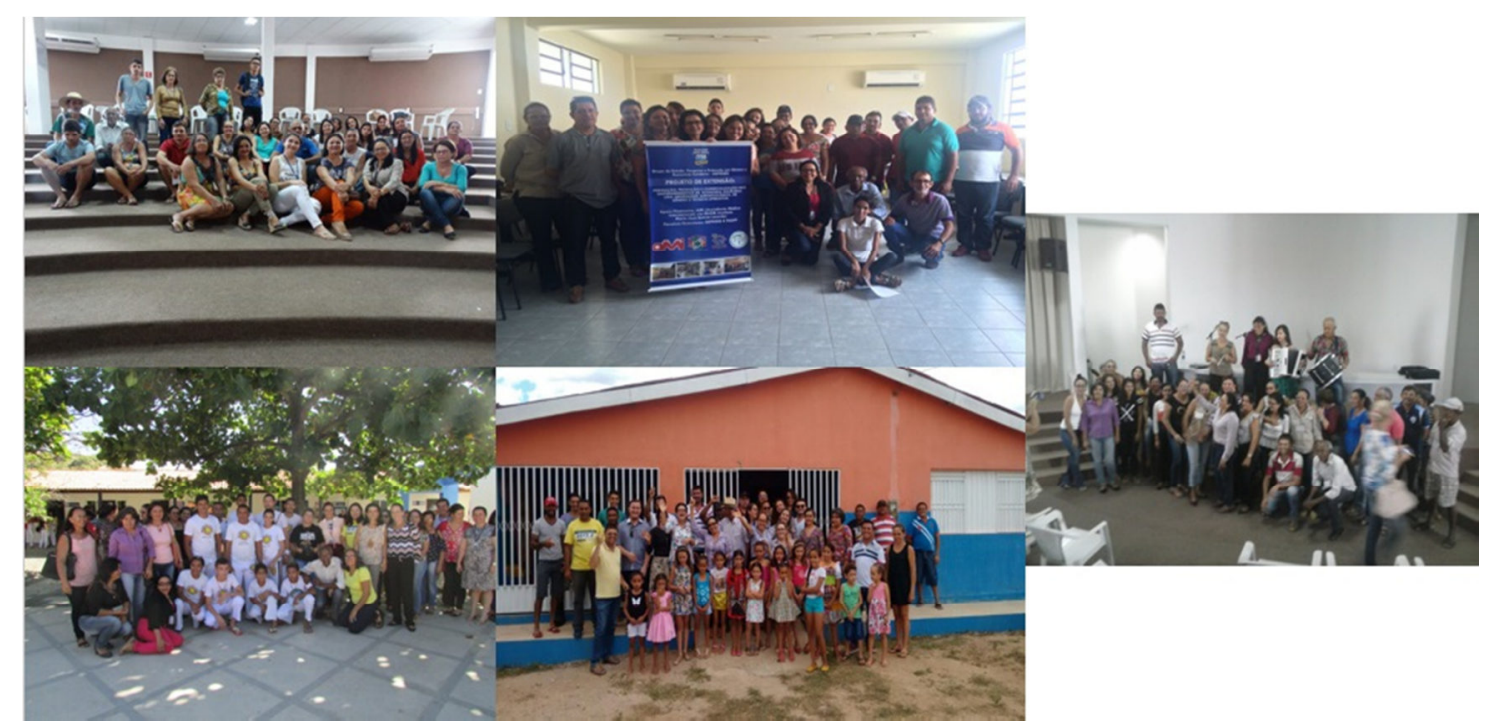

FONTE: Autores.

Esses momentos foram ricos na interação de saberes e na divulgação de outro modelo de produção e consumo. Em depoimento sobre a importância da formação para as empreendedoras, uma delas assim se posicionou:

Os processos de interação nestas capacitações desenham experiências inovadoras pautadas a valores e princípios responsáveis pela mitigação das práticas de exclusão social, degradação do ambiente, concorrência e acumulação, princípios presentes na produção do sistema capitalista. As formações estão promovendo uma troca de experiências e conhecimento que contribuíram com o empoderamento econômico, social e políticos capaz de formar cidadãos críticos com condições de contribuir com as inovações na reestruturação do tecido social, produtivo e político das comunidades e assentamentos rurais. (Membro do empreendimento de economia solidária Fonte do Sabor, 2017).

O depoimento deixa transparecer que a metodologia usada no projeto de extensão se coaduna com a indicada por Paulo Freire, 2006, em sua obra Extensão ou comunicação?, na qual, afirma ele, o diálogo na construção do conhecimento é eficaz na medida em que as ações proporcionam a construção de mundo, de cultura, de história e a construção de si mesmo como sujeito. A empreendedora é 
agora a pessoa que fala, projeta mudanças nos diferentes aspectos da vida, ou seja, na economia, na política e nas relações sociais.

Da perspectiva de gênero, sobressai em sua fala a expressão "empoderamento econômico", o que significa possibilidade libertadora para a mulher sertaneja, que experimenta há séculos, além da exclusão social, do estereótipo de gênero, da desigualdade econômica, o estigma de ser nordestina. O empenho coletivo fortalece as mulheres como protagonistas de novas formas e caminhos para a melhoria de sua condição de mulher, esposa, mãe e sujeito político (CRUZ, 2014), e, mais recentemente, de autogestora de economia solidária.

Ao ser perguntada sobre a importância da formação para seu trabalho no empreendimento, ela respondeu:

De suma importância por contribuir com minha formação profissional de extensionista que trabalha diariamente com este público desenhando novos caminhos e trajetórias para melhorar meu trabalho e minha pessoa enquanto ser humano. Compreender qual o modelo de desenvolvimento local que vem sendo trabalhado pelos empreendimentos da economia solidária nos assentamentos rurais do semiárido paraibano a partir dos conhecimentos e trocas de experiências vivenciadas nestas capacitações que estão sendo ministradas por pessoas competentes e conhecedores das causas, problemas e vivências de agricultores, assentados e empreendimentos de Economia Solidária (Gestora do empreendimento Fonte do Sabor, 2017).

A experiência vivenciada pela gestora de economia solidária no processo de formação possibilitou-lhe expressar o entendimento sobre sua prática, agora no papel de partícipe de um processo de produção e consumo que aponta para novo modelo de desenvolvimento local gestado nos empreendimentos ES (economia solidária), nos assentamentos da reforma agrária, no sertão paraibano. Retomando Singer (2002), percebemos que a troca de conhecimento entre os atores remete ao princípio da socialização entre os coletivos não apenas dos produtos, dos recursos, mas também dos saberes e experiências cultivados nos processos de produção da economia solidária. 
Outra empreendedora em seu depoimento apontou para o aspecto da cidadania, que desperta a necessidade de exigir, de cobrar os seus direitos aos órgãos públicos: "o curso nos ensina a procurar os nossos direitos e exercê-los, como também nossos deveres. Incentiva a produzir mais e de uma forma com mais quantidade e qualidade. Como também buscar maior qualificação" (Gestora de economia solidária do empreendimento GRUBAS - Grupo de Beneficiamento de Alimentos Sertanejos - 2017).

Quanto à organização para a comercialização dos produtos, já é possível constatar avanços, dentre os quais destacamos as várias reuniões dos gestores de ES, durante os encontros de formação, com outros órgãos, como PASP, CAASP, Secretaria de Economia Solidária do Estado, a fim de se discutir uma saída para a comercialização dos produtos daqueles empreendimentos que não conseguem cumprir as exigências das normas vigentes da vigilância sanitária bem como da Normativa 007/99 do Ministério da Agricultura, Pecuária e Abastecimento (MAPA).

Com a exigência dos padrões internacionais para importação, ficou mais difícil o cumprimento das metas por todos os elos da cadeia - desde a produção, processamento, distribuição até a certificação da qualidade dos produtos orgânicos de origem animal ou vegetal. Isso porque a maioria dos empreendimentos ainda funciona na informalidade, principalmente, aqueles autogestados por mulheres. Nossa expectativa é que, até o final dos cursos previsto para novembro próximo, tenha sido encontrada a solução para esse grande entrave.

Outro aspecto que cresceu com o processo formativo foi a divulgação das diferentes produções dos empreendimentos: antes, os gestores, pela dificuldade de deslocamento, ficavam isolados; agora, com a rotatividade dos encontros e a exposição dos produtos, despertou-se o interesse nos promotores de eventos. Um exemplo foi o IV SIMPÓSIO PARAIBANO DE ANATOMIA - UMA ABORDAGEM MULTIDISCIPLINAR E APLICADA organizado por professores da FSM e de outras instituições de ensino no sertão da Paraíba. Os responsáveis pelo evento formaram uma comissão que negociou com os empreendedores e empreendedoras que os lanches servidos nos coquetéis do evento e as lembranças para os palestrantes seriam produzidos pelos empreendimentos de economia solidária; além do mais, 
estes seriam convidados a expor seus produtos durante o evento, o qual reuniria acadêmicos e professores de todo o Brasil e participantes internacionais.

\section{CONSIDERAÇÕES FINAIS}

O projeto de extensão Formação, produção e comercialização nos empreendimentos de economia solidária: uma abordagem de gênero, agroecológica e técnico-operativa, em andamento, vem mostrando resultado significativo. Um dos pontos mais animadores reside no fato de que os quatro empreendimentos selecionados retomaram as atividades com muito entusiasmo, logo após o recebimento dos materiais de trabalho e dos equipamentos.

Além da geração de emprego e renda, percebemos a expectativa de empoderamento das gestoras, o que eleva a autoestima das participantes e traz a alegria de ter assegurado um trabalho de forma solidária. $E$ mais: devemos considerar o bem-estar social e a consciência ecológica, que caminham de mãos dadas com esse modelo de economia - a solidariedade visível com os companheiros e companheiras.

Quanto aos estudantes engajados no projeto, estão desenvolvendo comportamento diferenciado nas relações com os comunitários e na concepção sobre conhecimento. Com certeza, passam a reconhecer que a academia não é a única fonte do saber. Assim, a extensão universitária vai revelando-se como mais uma porta de acesso ao crescimento pessoal e profissional.

Podemos como educadores perceber que, pelo andamento do projeto, os professores, os estudantes e os voluntários demonstram adesão a um comportamento que vai restringindo a competição. Os encontros de formação estimulam a partilha de experiência e dos desafios; logo, os gestores podem juntos construir saídas. Nesse sentido, ao final do semestre, foi criada a Associação de Empreendedores de Economia Solidária e Artesãos de Cajazeiras, para vender os produtos provenientes dos empreendimentos aqui estudados, inclusive, dos informais. 
Em síntese, a produção do conhecimento, por meio da extensão, vem construindo-se da rica troca de experiência organizada e sistematicamente, tendo como princípio filosófico a democratização da informação. A participação ativa das comunidades na ação da universidade gera um impacto positivo tanto para os extensionistas quanto para os comunitários.

\section{REFERÊNCIAS BIBLIOGRÁFICAS}

Boff, Leonardo. (2014) A grande transformação: na economia, na política e na ecologia. Petrópolis-RJ: Vozes.

Brasil. (1996) Lei de diretrizes e bases da educação nacional. Lei número 9394, 20 de dezembro.

Carrasco, C. (1999). Mujeres y economía. Nuevas perspectivas para viejos problemas. Barcelona: Icaria.

Carvalho, Bernardina Silva; Albuquerque, Maria das dores; Gondim, Patrícia G. Corrêa. (2011) Teia do saber:saberes que convergem para o eixo complexo de práticas educativas. João Pessoa: Editora Universitária.

Cruz, Lindalva Alves. (2014) Construção da cidadania das mulheres trabalhadoras rurais no Piauí. 2 ed. Teresina, editora: Nova Aliança.

Fórum Nacional 1987: I Fórum Nacional de Pró-Reitores de Extensão de Universidades Públicas. (1993) Brasília.

Francisco, G; Carvalho, B, S. (2011). A prática extensionista da Universidade Federal da Paraíba à luz dos princípios da educação popular. Orientação de outra natureza; (Licenciatura Plena em Pedagogia) - Universidade Federal da Paraíba; Orientadora: Bernardina Silva de Carvalho.

Freire, Paulo. (2006). Pedagogia da autonomia: saberes necessários à prática educativa. 34 ed. Rio de Janeiro: Paz e Terra.

Freire, Paulo. (1973). Extensão ou comunicação? Rio de Janeiro: Paz e Terra.

Hirata, H. \& Kergoat, D. (2003). A divisão sexual do trabalho revisitada. In M. Maruani \& H. Hirata (Orgs.). As novas fronteiras da desigualdade homens e mulheres no mercado de trabalho (pp. 111-123). São Paulo: SENAC.

Hirata, H. (2002). Nova divisão sexual do trabalho? Um olhar voltado para a empresa e a sociedade. São Paulo, SP: Boitempo Editorial.

Kergoat, D. (1996). Relações sociais de sexo e divisão sexual do trabalho. In M. Lopes, D. Meyer \& V. Waldow (Orgs.). Gênero e Saúde (p. 156). Porto Alegre: Artes Médicas.

Nobre, M. (2002). Introdução a economia feminista. In M. Nobre \& N. Faria (Orgs.). Economia feminista. Cadernos sempre viva. SOF, São Paulo. 
Ortiz Roca, H. (2001). Economia solidária, Hacia una nueva civilización. Lima.

Polanyi, K. (2000). A grande transformação: as origens da nossa época. 9 ed. Rio de Janeiro: Editora Campus, Tradução de The Great Transformation, publicado, originalmente por Reinhart \& Company (1944).

Silva, N. F. (2009). A análise sobre a participação das mulheres e suas organizações na economia solidária no Brasil. Relatório de Pesquisa. REDES/IICA - MDA - NEAD - Brasília.

Singer, P. (2002). Introdução a economia solidária. São Paulo: Editora Fundação Perseu Abramo.

Strassmann, D. (2002). A economia feminista. In N. Farias \& M. Nobre (Orgs.). Economia feminista. SOF, São Paulo.

Tavares, C. Andrade Regis, Freitas, Katia, Siqueira de (2016). Extensão universitária o patinho feio da academia? Jundiai: Paco Editorial. 